\title{
French national survey of dog and cat owners on the deworming behaviour and lifestyle of pets associated with the risk of endoparasites
}

\author{
Clarisse Roussel $^{1 *}$, Jason Drake ${ }^{2}$ and Juan Manuel Ariza ${ }^{3}$
}

\begin{abstract}
Background: Endoparasites in dogs and cats are a concern related to pet health and zoonotic risks. Several determinants may affect the endoparasite transmission and infection of dogs and cats such as pet's lifestyle or regional parasite distribution. Although different zoonotic endoparasites, such as Toxocara spp. and Echinococcus spp., have been identified in France, little information exists about the deworming behaviors of owners or the frequency of occurrence of risk factors associated with endoparasite infection or transmission. Deworming guidelines, such as those created by the European Scientific Counsel Companion Animal Parasites (ESCCAP), recommend a deworming frequency according to the risk of infection of every pet and the potential risk for zoonotic transmission. The objectives of this study were to explore how lifestyles of dogs and cats from France were related to a particular risk of endoparasites and assess whether deworming frequencies complied with ESCCAP recommendations.
\end{abstract}

Methods: French data were extracted from a database created during a recent European pet owner survey regarding endoparasitic infection risk. Dogs and cats were grouped into risk categories based upon the ESCCAP guidelines. The compliance between the actual and recommended deworming frequencies were explored among the regions surveyed.

Results: The majority of dogs and cats were older than 6 months, had outdoor access, had contact with children or elderly people, and lived in rural and town areas. Most of the dogs were in contact with other dogs, snails or prey (83\%), and ate slugs, snails, grass or dug in the garden (68\%). Likewise, most of the cats hunted outside (57\%) and caught prey animals (52\%). Consequently, most of the dogs (89\%) and cats (53\%) were considered to be in the highest-risk category (D). However, independent of the region, the average deworming compliance for dogs was poor (6\%). While deworming compliance for cats in category A (low-risk) was excellent (94\%), for cats in category D it was poor (6\%).

Conclusions: Deworming compliance is needed to enhance pet health and reduce zoonotic risks. Future studies are warranted to thoroughly investigate the compliance and effectiveness of deworming protocols, and the risk factors associated with endoparasites in France.

Keywords: ESCCAP, Deworming recommendations, Risk factors, Helminths, Zoonosis, Companion animals, France

\footnotetext{
*Correspondence: ariza_clarisse@elanco.com

1 Elanco Animal Health, Lilly House, 24 boulevard Vital Bouhot, CS 50004,

92521 Neuilly sur Seine Cedex, France

Full list of author information is available at the end of the article
} 


\section{Background}

Endoparasites, particularly helminths, infect an important number of dogs and cats in Europe. Depending on the parasite involved, the severity of the clinical conditions associated with infection may vary from slight gastrointestinal signs to life-threatening situations [1, 2]. Moreover, some parasites represent a significant concern for public health because of their zoonotic potential. Recent European reports have revealed endoparasite prevalences ranging between $9-69 \%$ in dogs [3-14] and $8-40 \%$ in cats $[3,5-8,13,15,16]$. However, the prevalence of endoparasites is a specific population measure at a given time that is affected by several determinants including the design of the study [17], the season [18, 19], the geographical location [12, 20], the tools implemented for the diagnosis [21], and the lifestyle of the population studied (household or shelter animals) [9-11, 14]. In France, scarce data are available about endoparasite prevalence in dogs and cats, especially for helminths, with the last national report from 1997 reporting that $22 \%$ of dogs and $17 \%$ of cats were infected by endoparasites. Moreover, there is little information about the main factors influencing endoparasites in small animals in France [20].

Among zoonotic helminths present in France, Toxocara spp. and Echinococcus spp. are some of the most important infecting dogs and cats. In environments highly contaminated by both parasites, humans typically become infected by ingestion of infective eggs. Responsible for human toxocariasis, Toxocara spp. is the most frequent nematode found in dogs $(9.7 \%)$ and cats $(14.3 \%)$. Whereas infection rates of Echinococcus multilocularis in dogs $(0.4 \%)$ and cats $(1.5 \%)$ appear to be low, prevalence of more than $10 \%$ has been reported in red foxes (main final host) in France, being one of the highest in Europe [22]. During the last decade, the parasite has spread over 25 new localities within France, including southern regions and urban areas like Paris [23, 24]. Echinococcus multilocularis is responsible for the dangerous alveolar echinococcosis (AE) in humans. Although, historically is considered a rare disease, the number of cases has increased in Europe, particularly in France, during the past few decades [25-27]. Concerning Echinococcus granulosus, responsible for the cystic echinococcosis (CE) in humans, little is known about its prevalence in French dogs. Nevertheless, data from intermediate hosts (sheep, cattle, pigs, goats, horses or cervids) collected in slaughterhouses confirming that the parasite is present across the country, though in a low prevalence [28-30].

While Toxocara spp. and Echinococcus spp. represent major zoonotic threats to public health, they have a smaller impact on the animal's health (none to mild signs of disease). Conversely, helminths such as Angiostrongylus vasorum and Dirofilaria immitis, represent an important threat for the welfare and health of small animals in France. Although A. vasorum and Dirofilaria spp. were previously considered of low prevalence in Europe, different factors have allowed the spread of those parasites, including: (i) climate change and the consequent ecological changes on intermediate hosts (i.e. slugs, snails for $A$. vasorum and mosquitoes for $D$. immitis); (ii) increased trade and movement of pets; and (iii) the reservoir-vector diversification (i.e. Aedes albopictus) [2, 19]. Angiostrongylus vasorum is primarily a parasite of Canidae, being mainly responsible for cardiorespiratory signs and less frequently for coagulopathies and neurologic disorders [2]. The parasite prevalence in France ranges from $1.4 \%$ to $11.8 \%$ [18, 31, 32]. Dirofilaria immitis affects mainly dogs, however other hosts, such as cats, ferrets, foxes and wolves, may be affected as they can be involved in the live-cycle of the parasite [1, 19]. Dogs infected with the parasite develop a progressive cardiopulmonary disease [1]. In France, the parasite is distributed in the southern regions, the Corse and in some French overseas territories (Martinique and French Guyana among others) with reporting prevalence rates ranging between $0.22-6.8 \%$ [19, 33, 34]. Regarding its zoonotic potential, the parasite is responsible for the benign pulmonary dirofilariasis in humans. Dirofilaria repens, in contrast, is responsible for ocular and cutaneous dirofilariasis in humans, with a number of cases that have increased recently ( 23 cases reported between 1995 and 1999 versus 63 cases between 2000 and 2011 in France) [1, 35-37]. Small animals infected typically present minor or even no signs of disease $[1,19,38]$. Additionally, it is worth mentioning that in France, the parasite Thelazia callipaeda have been recently identified throughout the south-western region of the country [39]. The distribution of this parasite is related to the presence of the intermediate host, the fruit fly Phortica variegata. This eyeworm can cause ocular problems such as blepharospasm, epiphora, conjunctivitis, keratitis and corneal ulcers in dogs, cats, foxes and lagomorphs. Although $T$. callipaeda is a recognized agent of a zoonosis responsible for similar ocular symptoms as seen in animals, only a few human cases have been reported in France [40].

In order to control the zoonotic risk posed by endoparasites, and to increase the welfare and the health of small companion animals, ESCCAP has developed deworming guidelines aimed to reduce the environmental infection pressure and parasitic infections of small animals. These guidelines are based on the main risk factors associated with endoparasites identified across the scientific evidence on endoparasite control of dogs and cats. According to ESCCAP, the assessment of the lifestyle and the physiological status of animals should guide veterinarians in the deworming decision-making process. Currently, 
the ESCCAP guidelines propose four main categories (A, $\mathrm{B}, \mathrm{C}$ and $\mathrm{D}$ ) for dogs and two main categories (A and $\mathrm{B}$ ) for cats associated with particular risk factors and advise a deworming frequency for each category [41]. Nevertheless, even with available guidelines, owners and veterinarians do not always follow the experts' recommendations [42], suggesting that there is a lack of concern or awareness regarding the parasites and the risks associated with infection.

To explore the endoparasitic risks associated with the lifestyle of dogs and cats in France, we explored and analysed the results of a recent European survey on small companion animals lifestyle and pet owners deworming behavior. Additionally, we explored whether pet owners' deworming behavior in France follows the recommended deworming frequency.

\section{Methods}

\section{Study design}

The lifestyle of dogs and cats and the deworming behavior of pet owners were explored through an online survey conducted in five European countries in July 2017 [43]. The information recorded from the French territories is presented and investigated at regional levels in this manuscript.

The methodology implemented in the survey has been described in detail in the previous publication [43]. Briefly, the surveyed cat or dog owners were at least 18 years-old, were responsible for the pet health care of fewer than 10 animals and owned pets examined by a veterinarian at least once a year. Owners who used their animals for any professional reasons were excluded from the survey. These criteria were established to homogenize the studied population to typical pet owner households.
In cases where an owner owned both a cat and dog, the owner was randomly provided the survey of only one species.

A total of 19,855 French owners were recruited from a database panel through a link to fulfill the online survey in order to achieve a representative sample composed by 1000 owners of 500 cats and 500 dogs according to recent demographic statistics about pet-owning households. Small incentives were offered to owners to encourage survey completion. Once the quotas of 500 cat owner and 500 dog owner surveys were reached, the online survey was closed to prevent further submissions.

The survey questionnaire (Table 1) was created to allow classification of dogs and cats into 4 risk categories according to their lifestyle, additional factors affecting their exposure and infection, and potential zoonotic concerns. ESCCAP suggests 4 risk groups for dogs and only 2 for cats. To facilitate direct comparison between cats and dogs as well as group higher risk cats into the appropriate deworming frequency, the ESCCAP risk groups for cats (A-B) were converted into four risk groups (A-D) using the additional risk factors outlined in the ESCCAP guidelines [41]. For each category, an ESCCAP recommended deworming frequency is associated (Table 2). The questionnaire comprised general questions, including one related to the characteristics and the geo-localization of the responder's residence, one about deworming frequency, and six (cats) or eight (dogs) related to the lifestyle of their cat or dog. Additional questions related to commercial deworming products and the relationship between owners and veterinarians were included in the survey but were not explored in this paper. The questions related to the lifestyle of the animals and the deworming behavior of owners were dichotomous (answers Yes

Table 1 Questionnaire for dog and cat owners

\begin{tabular}{|c|c|c|}
\hline $\begin{array}{l}\text { Question } \\
\text { number }\end{array}$ & Question for dog owners & Question for cat owners \\
\hline 1 & $\begin{array}{l}\text { Which of the following categories describes best the place you live in? } \\
\text { Rural area, town, suburban, city? }\end{array}$ & $\begin{array}{l}\text { Which of the following categories describes best the place you } \\
\text { live in? Rural area, town, suburban, city? }\end{array}$ \\
\hline 2 & How often do you currently deworm your dog? & How often do you currently deworm your cat? \\
\hline 3 & Is your dog less than 6 months-old? & Is your cat less than 6 months-old? \\
\hline 4 & $\begin{array}{l}\text { Is your dog exercising only in your own garden? (no contact with public } \\
\text { places, other dogs, slugs, snails, raw meat or prey animals) }\end{array}$ & Is your cat kept indoors all the time (and does not eat raw meat)? \\
\hline 5 & Does your dog exercise off the lead? & Does your cat hunt outside? \\
\hline 6 & $\begin{array}{l}\text { Does your dog ever get in contact with other dogs, slugs, snails or prey } \\
\text { animals? }\end{array}$ & Does your cat ever catch prey such as mice and birds? \\
\hline 7 & Does your dog eat slugs, snails, grass or dig in the garden? & Does your cat eat raw meat? \\
\hline 8 & $\begin{array}{l}\text { Does your dog ever catch animals such as rabbits or mice or pick up } \\
\text { carcasses? }\end{array}$ & Does your cat interact with children or the elderly? \\
\hline 9 & Does your dog eat any raw meat? & \\
\hline 10 & Does your dog interact with children or the elderly? & \\
\hline
\end{tabular}




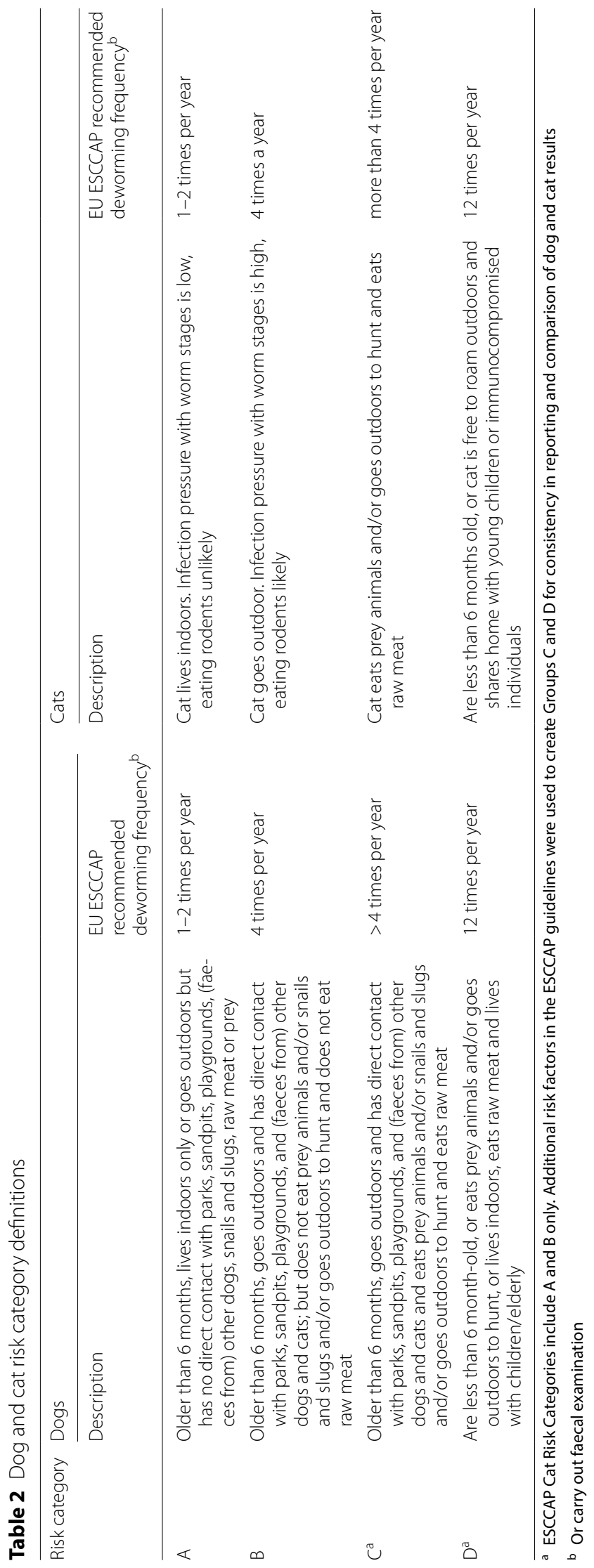


or No). Questions related to owner behavior were placed at the beginning of the questionnaire in order to avoid potential influence on the rest of the questions. Surveys were confidential and each owner was informed of the purpose of the survey and accepted the terms of the study.

\section{Data analysis}

For each region, dogs and cats were grouped according to their lifestyles into one of the four risk categories created from the ESCCAP guidelines without taking into account the endemic risk associated with the presence of some parasites on the French territories (Table 2). The recommended deworming frequencies for each risk category were adapted based on local risk assessments (Table 3).

To determine the compliance between the current owner deworming practices and the ESCCAP deworming recommendations, the proportions of dogs and cats dewormed complying with the deworming recommendations were calculated for each region. In general, animals were considered compliantly dewormed if: (i) animals in category A were dewormed at least once a year; (ii) animals in category B were dewormed at least 3 times per year; (iii) animals in category $C$ were dewormed at least 5 times per year; and finally, (iv) animals in category D were dewormed at least 6 times a year. According to the proportion of dogs and cats following the deworming recommendations, in each region compliance was considered as excellent ( $>90 \%)$, good $(60-90 \%)$, moderate $(40-60 \%)$ and poor $(<40 \%)$.

\section{Translation}

French translation of the Abstract is provided in Additional file 1 .

Table 3 Dog and cat recommended deworming frequencies in France

\begin{tabular}{|c|c|c|}
\hline $\mathrm{Dog} / \mathrm{Cat}^{\mathrm{a}}$ & Dog & Cat \\
\hline Puppy/ Kitten & Monthly & Monthly \\
\hline $\begin{array}{l}\text { Only exercised in garden, super- } \\
\text { vised/Indoor }\end{array}$ & $1-2 \times$ yearly & $1-2 \times$ yearly \\
\hline nab/Outdoor & $n a^{b}$ & $4 \times$ yearly \\
\hline Catches animals/ Eats prey & Monthly & $>4 \times$ yearly \\
\hline With children, elderly & Monthly & Monthly \\
\hline Allowed off-lead/ nab & $>4 \times$ yearly & $n a^{b}$ \\
\hline Fed, eats raw meat & $>4 \times$ yearly & $>4 \times$ yearly \\
\hline Eats slugs, snails/ na ${ }^{b}$ & Monthly & $n a^{b}$ \\
\hline
\end{tabular}

a if "Yes" in survey

b na: not applicable

\section{Results}

From the 19,855 French owners contacted, only 1984 followed the invitation and visited the entry page. Of those, 71 cancelled the survey before completion. Additionally, 738 surveys did not match the inclusion criteria. Finally, 175 were excluded after the database reached the targeted fixed population of $500 \mathrm{dog}$ owners and 500 cat owners. On average, 38 dog owners and 38 cat owners responded the survey by region (responders ranged from 3 to 96). The Corse region was underrepresented with only three $\operatorname{dog}$ and three cat responders.

\section{Dogs}

Table 4 presents the main lifestyles of dogs and the deworming behaviour of owners for each region. In general, independent of the region surveyed, most dogs: (i) were older than 6 months (97\%); (ii) were kept on lead when outside (83\%); (iii) were in contact with other dogs, snails or prey (83\%); (iv) ate slugs, snails, grass or dug in the garden (68\%); and (v) were in contact with children and/or elderly people (75\%). Furthermore, most of the responders lived in rural areas $(44 \%)$ or in towns $(29 \%)$. The proportion of dogs having outdoor access in addition to their own garden varied between the regions from 43\% (Nouvelle-Aquitaine) to $80 \%$ (Bretagne). Additionally, of the dogs having outdoor access, between 20\% (Ile-de-France) and 45\% (Bretagne) went "off lead". Finally, the proportion of owners reporting that their dogs caught prey animals varied from 10\% (Grand Est) to 30\% (Hauts-de-France).

Among the regions studied, dogs were dewormed between 1.50 and 3 times per year (2.28 on average) (Table 4). According to the risk category classification, $2 \%, 2 \%, 7 \%$ and $89 \%$ of the dogs were grouped into categories A (lowest risk), B, C and D (highest risk), respectively (Table 6). The overall compliance of dog owners with the deworming recommendations for each region is presented in Fig 1. It ranges from approximately $2 \%$ (Auvergne-Rhônes-Alpes) to 13\% (Grand Est). For Category D, where most of the dogs were grouped, on average the compliance was poor (4\%) within the regions fluctuating from 0\% (Auvergne-Rhône-Alpes, Bretagne, Provence-Alpes-Côte d'Azur and Corse) to 13\% (Grand Est). For the remaining categories (A, B and C) represented by small numbers of individuals, the overall compliance varied between poor for category $\mathrm{C}$ $(0 \%)$ and category B (36\%), to excellent for category A (100\%). Finally, across France the average compliance with the recommended deworming was poor (6\%). 
housel et al. Parasites Vectors $\quad$ (2019) 12:480

Page 6 of 13

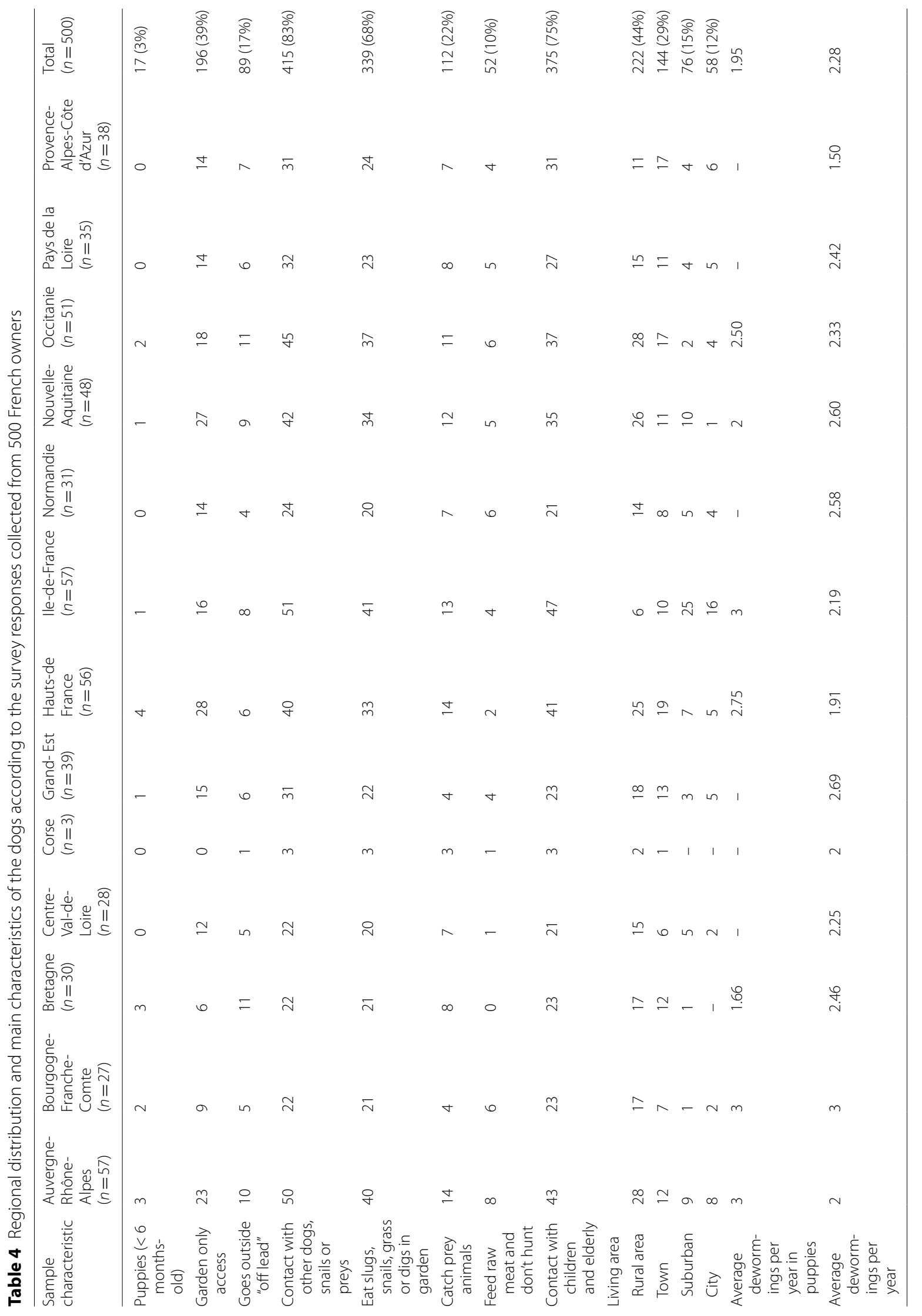




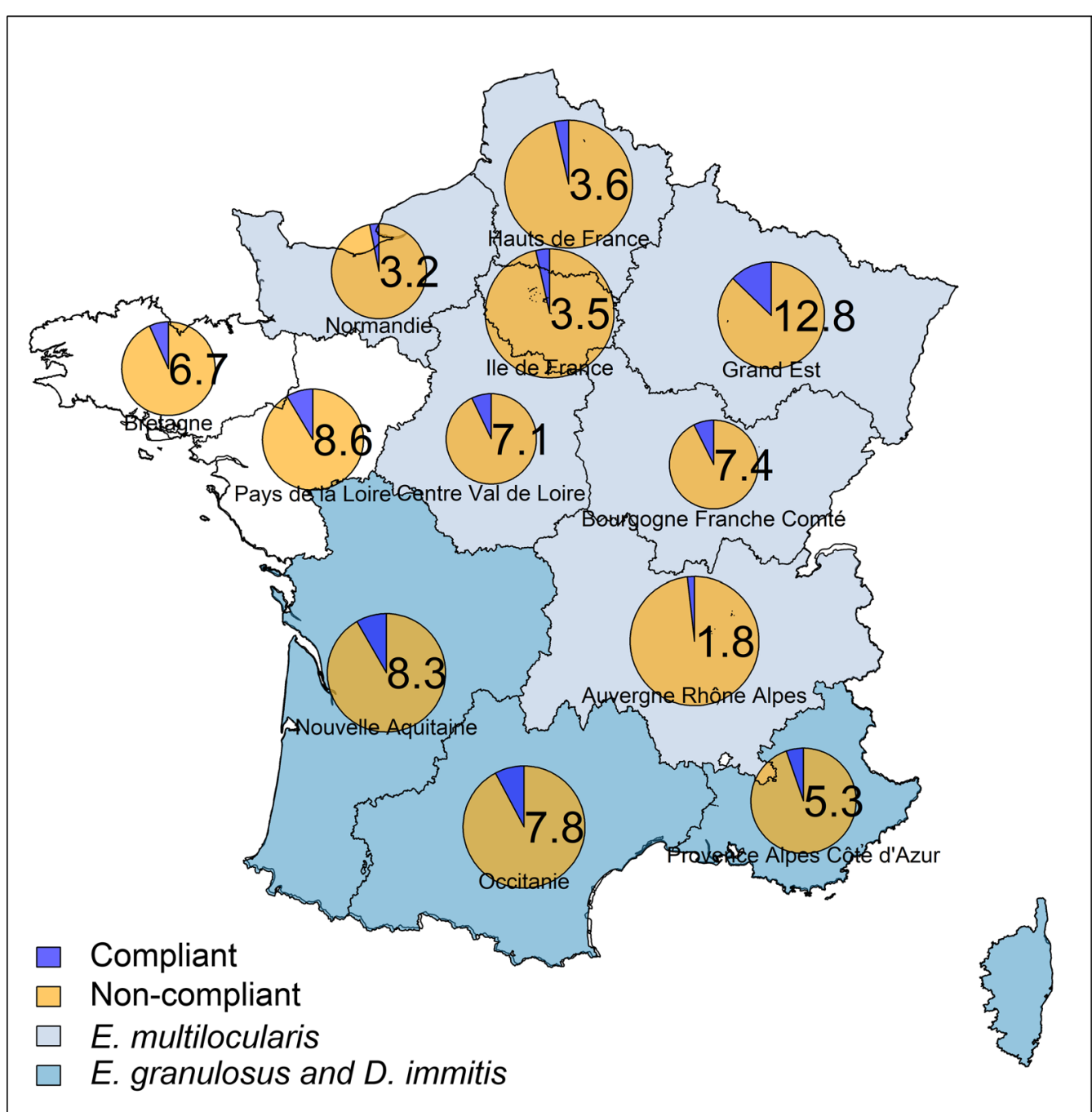

Fig. 1 Proportion (\%) of dog owners deworming in compliance with ESCCAP risk-based recommendations. Size of the pie is proportional to the size of sample surveyed. Regions are coloured according to the presence of parasites of zoonotic concern

\section{Cats}

Table 5 presents the main lifestyles of cats and the deworming behaviours of owners for each region. Most of the cats from the survey were older than 6 months (97\%) and had outdoor access (66\%). The cat owners mostly reported living in rural areas (31\%) and towns $(32 \%)$. While only $5 \%$ of the responders fed their cats raw meat, overall, $57 \%$ (33\% to 68\%) reported living with children or elderly people, $57 \%$ (33\% to $72 \%$ ) hunted outside and $52 \%$ (33\% to $65 \%$ ) caught prey animals. Among the regions studied, cats were dewormed between 1.33 and 3 times per year (2.25 on average). Across the country 33\%, 3\%, 11\% and 53\% cats were grouped in categories A (lowest risk), B, C and $\mathrm{D}$ (highest risk), respectively (Table 6). The overall compliance of cat owners with the deworming recommendations for each region is presented in Fig 2. Deworming compliance ranged from 28\% (NouvelleAquitaine, Occitanie) to $47 \%$ (Provence-Alpes-Côte d'Azur). Approximately half of the cats from the survey were in category $D$ for which compliance was poor (6\%) across all regions fluctuating from 0\% (CentreVal-de-Loire, Occitanie, Pays de la Loire and Corse) to 13\% (Bretagne and Normandie). For the cats grouped in category A the compliance was excellent (94\%). The remaining classes were composed by smaller numbers of individuals and the overall compliance was poor (category C $7.5 \%$ and category B $20 \%$ ). In conclusion, across France the average compliance with deworming recommendations was poor (36\%). 
housel et al. Parasites Vectors $\quad$ (2019) 12:480

Page 8 of 13

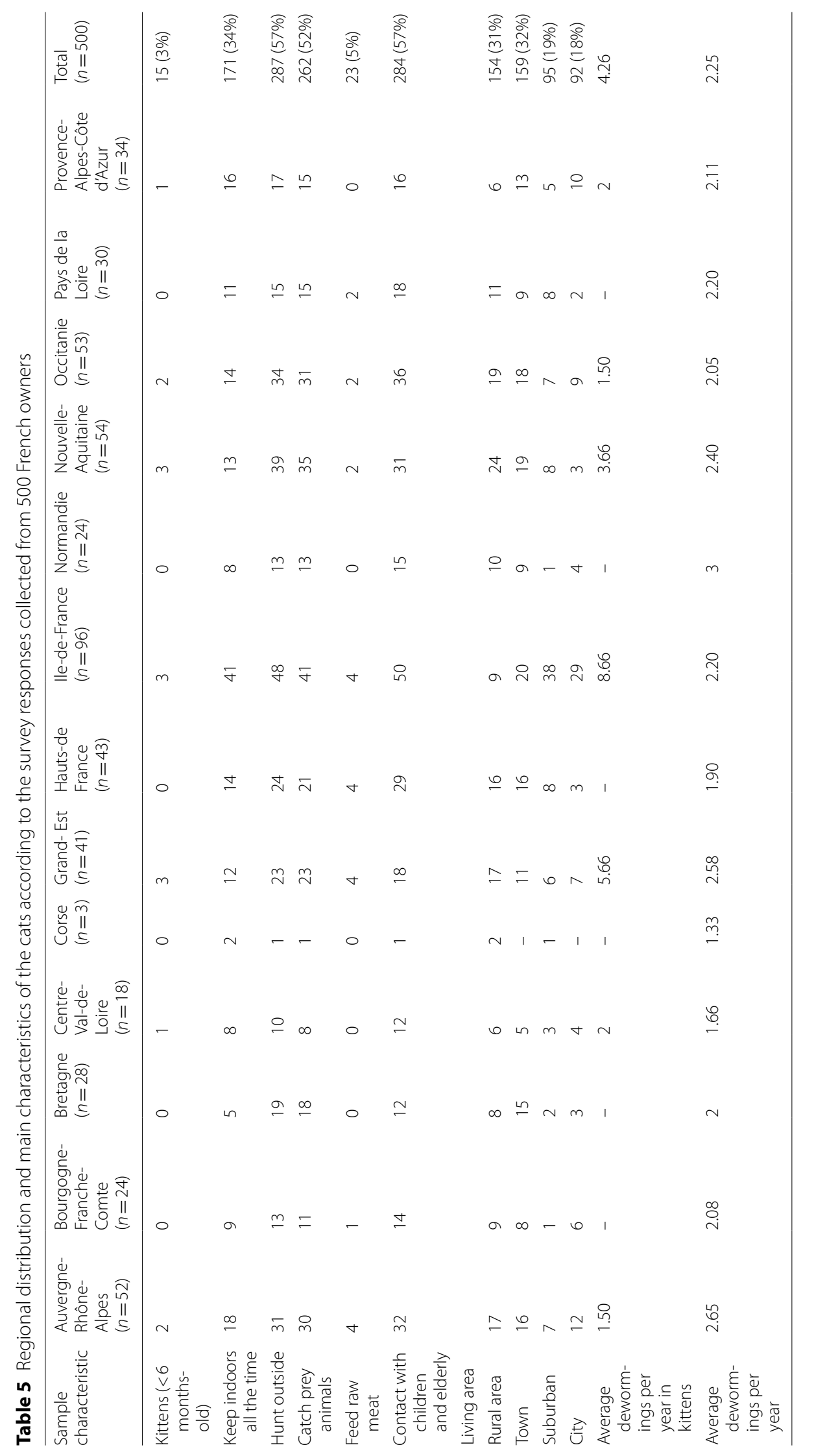


Table 6 National and regional distribution of dogs and cats according to the risk category classification implemented

\begin{tabular}{|c|c|c|c|c|c|c|c|c|c|c|}
\hline \multirow[t]{3}{*}{ Region } & \multicolumn{5}{|l|}{ Dog } & \multicolumn{5}{|l|}{ Cat } \\
\hline & \multicolumn{5}{|c|}{ Risk category, n (\%) } & \multicolumn{5}{|c|}{ Risk category, n (\%) } \\
\hline & A & $\mathrm{B}$ & C & $\mathrm{D}$ & $N$ (total) & A & B & C & $\mathrm{D}$ & $N$ (total) \\
\hline Auvergne-Rhône-Alpes & $1(2)$ & $2(3)$ & $10(18)$ & $44(77)$ & 57 & $15(29)$ & $3(6)$ & $10(19)$ & $24(46)$ & 52 \\
\hline Bourgogne-Franche-Comte & 0 & 0 & 0 & $27(100)$ & 27 & $9(37)$ & 0 & 0 & $15(63)$ & 24 \\
\hline Bretagne & $1(3)$ & $1(3)$ & $4(13)$ & $24(80)$ & 30 & $7(25)$ & $3(11)$ & $10(36)$ & $8(29)$ & 28 \\
\hline Centre-Val-de-Loire & 0 & $3(11)$ & $4(14)$ & $21(75)$ & 28 & $7(39)$ & $2(11)$ & $3(17)$ & $6(33)$ & 18 \\
\hline Corse & 0 & 0 & 0 & $3(100)$ & 3 & $2(67)$ & 0 & 0 & $1(33)$ & 3 \\
\hline Grand-Est & $2(5)$ & 0 & 0 & $37(95)$ & 39 & $12(29)$ & 0 & $28(68)$ & $13(30)$ & 41 \\
\hline Hauts-de France & $1(2)$ & 0 & 0 & $55(98)$ & 56 & $13(30)$ & 0 & $3(7)$ & $27(63)$ & 43 \\
\hline Ile-de-France & 0 & 0 & 0 & $56(100)$ & 57 & $38(40)$ & 0 & $1(1)$ & $57(59)$ & 96 \\
\hline Normandie & 0 & 0 & 0 & $31(100)$ & 31 & $8(33)$ & 0 & 0 & $16(67)$ & 24 \\
\hline Nouvelle-Aquitaine & $1(2)$ & $2(4)$ & $10(21)$ & $35(73)$ & 48 & $11(20)$ & $4(7)$ & $16(30)$ & $23(43)$ & 54 \\
\hline Occitanie & $1(2)$ & 0 & 0 & $50(98)$ & 51 & $16(30)$ & 0 & 0 & $37(70)$ & 53 \\
\hline Pays de la Loire & 0 & $3(9)$ & $5(14)$ & $27(77)$ & 35 & $10(33)$ & $3(10)$ & $9(30)$ & $8(27)$ & 30 \\
\hline Provence-Alpes-Côte d'Azur & $2(5)$ & 0 & 0 & $36(95)$ & 38 & $17(50)$ & 0 & 0 & $17(50)$ & 34 \\
\hline Total & $10(2)$ & $11(2)$ & $33(7)$ & $446(89)$ & 500 & $165(33)$ & $15(3)$ & $53(11)$ & $267(53)$ & 500 \\
\hline National compliance & $10(100)$ & $4(36)$ & 0 & $16(4)$ & & $155(94)$ & $3(20)$ & $4(7.5)$ & $17(6)$ & \\
\hline
\end{tabular}

\section{Discussion}

This study describes the main lifestyle factors related to endoparasites in cats and dogs and the associated deworming behaviors of their owners across the various regions of Metropolitan France (European France). The results of this survey indicate that, among the regions, the majority of dogs and cats share lifestyle factors associated with a high risk of endoparasite transmission and infection according to the ESCCAP-based risk categories. However, the recommended deworming frequency (monthly) for those dogs and cats was largely not followed (only 4\% for dogs and 6\% for cats). Selection bias may have affected the classification of the animals. This survey was designed to randomly select the study population, but owners particularly interested in the subject may have been more likely to complete the survey. Likewise, other factors not addressed by the questionnaire may have substantially affected the deworming behavior of the owner or the deworming advice of veterinarians and thereby affecting our appraisal of compliance.

Several determinants are involved in the process of endoparasite infection and transmission. As some endoparasites are transmitted to dogs and cats by vectors or by direct or indirect contact with intermediate hosts, the distribution of the parasites may be limited to landscapes in which host and vectors share the same habitat, resulting in large differences in the risk of infection from region to region. Moreover, the parasite burden among different individuals is determined by multiple factors related to their lifestyle, as highlighted in previous studies $[15,16$,
44-46]. Nevertheless, the lifestyle of pets may substantially change over time and within countries. In France, the risk factors associated with endoparasites in dogs and cats have been scarcely studied [20, 21, 47]. A continued surveillance program of pets for endoparasite prevalence, lifestyle and deworming rates may benefit public health and welfare of pets.

From our findings, among the most frequent lifestyle factors associated with low deworming compliance were: (i) the contact with other dogs, slugs, snails and preys; and (ii) the interaction with children and elderly. Nevertheless, these factors were approached through broad questions that may contribute to placing a large part of the dog population at category $\mathrm{D}$. Therefore, further studies focused on the factors associated with the risk of pets endoparasites should enhance the precision of the lifestyle questionnaires to avoid potential selection bias when grouping the animals according to recognized risks. Nevertheless, although no specifics were obtained on the ages and the immunological status of the population surveyed in this study, the important zoonotic risk posed by Toxocara spp. on children and immune suppressed individuals is a concern that should guide the implementation of a comprehensive deworming protocol for pets in close contact with these populations.

This study documented low deworming levels which may be related to suboptimal client education and deworming protocols among the veterinary community, as reported by previous studies [48-51]. From our findings, dog owners reportedly dewormed their 


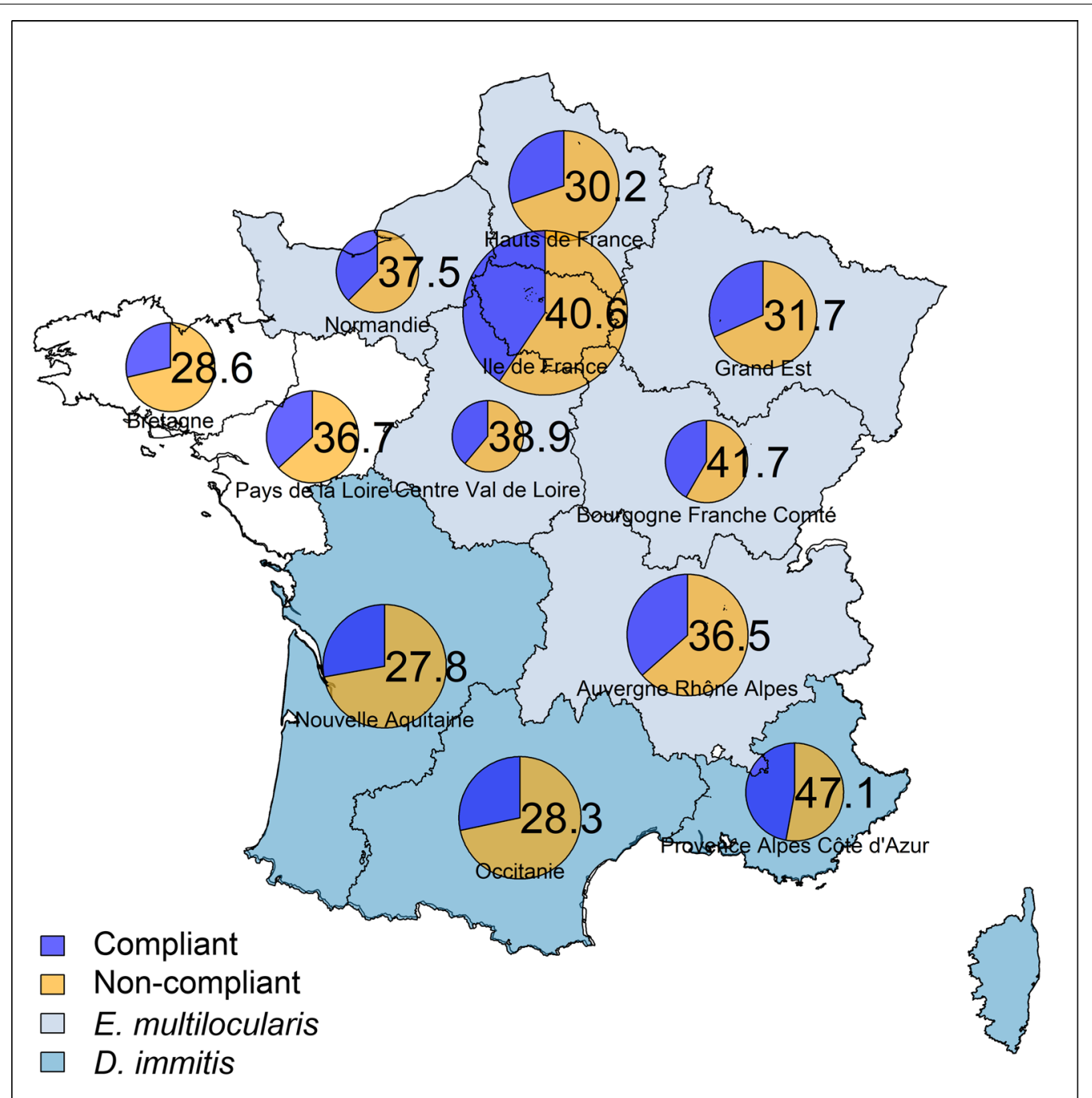

Fig. 2 Proportion (\%) of cat owners deworming in compliance with ESCCAP risk-based recommendations. Size of the pie is proportional to the size of sample surveyed. Regions are coloured according to the presence of parasites of zoonotic concern

animals only 2.28 times a year on average. In all the regions the deworming frequencies were well below the frequencies advised. The highest deworming frequency was 3 times per year recorded in the BourgogneFranche-Comté region. However, because of the presence of E. multilocularis, pet owners should be more concerned about deworming in this area. The same tendency was observed for cats, largely categorized in category D (53\%). Cat owners dewormed on average only 2.25 times per year instead of the monthly deworming recommendation for cats in this risk group. However, cats are considered poor hosts of E. multilocularis. Excreting only a few eggs in the environment, the risk of transmission is considerably reduced [52].
As pointed out above, although $\mathrm{AE}$ is a low incidence disease, the number of cases increased in Europe and specifically in France over the past few decades [25, 26]. Therefore, a special monitoring program for E. $\mathrm{mul}$ tilocularis has been developed in France through the National Reference Laboratory (NRL) for Echinococcus spp. in Nancy and the National Reference Centre (NRC) in Besançon. Although there is no legal reporting obligation of AE cases, the NRC has developed a network for recording $\mathrm{AE}$ cases between hospital centers, hospital pharmacies, and laboratories of pathology and parasitology throughout France [25, 26]. Living in rural areas is a factor frequently associated with $\mathrm{AE}$ cases. The majority of the population surveyed in this study reported living in 
rural areas and towns and owning pets that have contact with children and elderly people. The deworming frequencies recorded, however, were much lower than the advised frequencies. These findings highlight the importance of developing and implementing deworming guidelines adaptable to different pet's lifestyle scenarios.

Otherwise, regarding the spread of E. granulosus, although a recent study indicated that the already low incidence of CE decreased between 2005 and 2014 [53], the estimated incidences in Corse and Provence-AlpesCôte d'Azur regions remain the highest in France. Moreover, the parasite still affects intermediate hosts at low prevalence, mainly sheep and pig herds from the southeastern and Corse regions, respectively. [30]. Therefore, the infection risk for dogs is still present and should be a primary concern for deworming strategies.

The southern and Corse regions, and French administered territories as well, have been identified as endemic areas for $D$. immitis [19, 33, 34]. Nevertheless, despite the risk encountered by dogs and cats of those regions, owners seem largely unconcerned as revealed by the deworming rates recorded in southern regions. However, the implementation of other means of $D$. immitis prevention, such as repellents, may hide an alternative preventive behavior of owners. Regarding A. vasorum, known as the "French heartworm", which is mainly present in northern, southern and central regions (Ile de France), this parasite is considered to have national distribution $[18,31,32]$. Therefore, across the country, dog owners and veterinarians should be aware of the important risk that $A$. vasorum represent for dogs in contact with intermediate hosts such as slugs and snails. Regarding the risk of thelaziosis, during the last decade the parasite has been identified in new areas within France. The expansive spread of the parasite across the country could be explained as a consequence of the large dispersal of wild host reservoirs [54] and the suitability of the vector $P$. variegata thriving all over the country [55].

Finally, while there is little evidence supporting endoparasite resistance to anthelmintic drugs of dogs and cats, and multiple classes of anthelmintics are available for many species of nematodes, there is an increasing concern for minimizing this potential threat [56]. Therefore, the correct frequency and usage of antihelminthics is a priority for the development of effective and sustainable control strategies.

The low occurrence of deworming recorded during this survey highlight the importance of conducting future studies to investigate the changing deworming behaviours of owners and the deworming advice of veterinarians, especially for high-risk populations and recognized endemic regions. Increasing the owner's and veterinarian's compliance with deworming recommendations may significantly enhance the health and welfare of companion animals thereby reducing zoonotic risks $[57,58]$.

\section{Conclusions}

The results of this survey highlight the low deworming rates of dogs and cats within the French metropolitan territory. Independent of the lifestyle of the dogs and cats surveyed, the deworming behavior of owners did not match the advised guidelines needed to reduce the potential risk of endoparasites infection and transmission, and did not adequately increase in frequency as risk increased. Future studies are warranted to develop, promote and evaluate effective and regular deworming strategies based on the lifestyle of the pets. In the meantime, veterinarians and pet owners should implement the risk assessment and deworming guidelines provided by ESCCAP.

\section{Supplementary information}

Supplementary information accompanies this paper at https://doi. org/10.1186/s13071-019-3712-4.

Additional file 1: Text S1. French translation of the abstract.

\section{Abbreviations}

ESCCAP: European Scientific Counsel Companion Animal Parasites; AE: Alveolar Echinococcosis; CE: Cystic Echinococcosis; NRL: National Reference Laboratory; NRC: National Reference Centre.

\section{Acknowledgements}

The authors wish to thank Drs Ludger Rolfes and Andrea Bruns with "Produkt + Markt Marketing Research", Wallenhorst, Germany for conducting the survey.

\section{Authors' contributions}

JD participated in one or more of design, completion and reporting of the European survey. CR and JMA analysed the data and interpreted results for the current study. CR, JMA and JD drafted the manuscript. All authors revised critically the manuscript for important intellectual content. All authors read and approved the final manuscript.

\section{Funding}

Elanco funded the study.

\section{Availability of data and materials}

The datasets supporting the conclusions of this article are included within the article. Due to commercial confidentiality of the research, data not included in the manuscript can only be made available to bona fide researchers subject to a non-disclosure agreement.

\section{Ethics approval and consent to participate}

Not applicable.

\section{Consent for publication}

Not applicable.

Competing interests

CR and JD are employees of Elanco Animal Health. JMA declares that he has no competing interests. 


\section{Author details}

1 Elanco Animal Health, Lilly House, 24 boulevard Vital Bouhot, CS 50004, 92521 Neuilly sur Seine Cedex, France. ${ }^{2}$ Elanco Animal Health, 2500 Innovation Way, Greenfield, IN 46140, USA. ${ }^{3}$ Independent Researcher, Nantes, France.

\section{Received: 21 June 2019 Accepted: 12 September 2019} Published online: 14 October 2019

\section{References}

1. Simon F, Siles-Lucas M, Morchon R, Gonzalez-Miguel J, Mellado I, Carreton

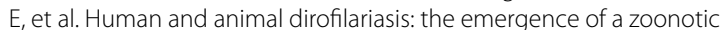
mosaic. Clin Microbiol Rev. 2012;25:507-44.

2. Helm JR, Morgan ER, Jackson MW, Wotton P, Bell R. Canine angiostrongylosis: an emerging disease in Europe. J Vet Emerg Crit Care. 2010:20:98-109.

3. Barutzki D, Schaper R. Endoparasites in dogs and cats in Germany 1999-2002. Parasitol Res. 2003;90(Suppl. 3):148-50.

4. Dubná S, Langrová I, Nápravník J, Jankovská I, Vadlejch J, Pekár S, et al. The prevalence of intestinal parasites in dogs from Prague, rural areas, and shelters of the Czech Republic. Vet Parasitol. 2007:145:120-8.

5. Gracenea M, Gómez MS, Torres J. Prevalence of intestinal parasites in shelter dogs and cats in the metropolitan area of Barcelona (Spain). Acta Parasitol. 2009;54:73-7.

6. Becker AC, Rohen M, Epe C, Schnieder T. Prevalence of endoparasites in stray and fostered dogs and cats in northern Germany. Parasitol Res. 2012;111:849-57.

7. Riggio F, Mannella R, Ariti G, Perrucci S. Intestinal and lung parasites in owned dogs and cats from central Italy. Vet Parasitol. 2013;193:78-84.

8. Barutzki D, Schaper R. Results of parasitological examinations of faecal samples from cats and dogs in Germany between 2003 and 2010. Parasitol Res. 2011;109(Suppl. 1):45-60.

9. Claerebout E, Casaert S, Dalemans AC, De Wilde N, Levecke B, Vercruysse $J$, et al. Giardia and other intestinal parasites in different dog populations in northern Belgium. Vet Parasitol. 2009;161:41-6.

10. De Liberato C, Berrilli F, Odorizi L, Scarcella R, Barni M, Amoruso C, et al. Parasites in stray dogs from Italy: prevalence, risk factors and management concerns. Acta Parasitol. 2018;63:27-32.

11. Martínez-Carrasco C, Berriatua E, Garijo M, Martínez J, Alonso F, Ybáñez R. Epidemiological study of non-systemic parasitism in dogs in Southeast mediterranean Spain assessed by coprological and post-mortem examination. Zoonoses Public Health. 2007;54:195-203.

12. Owen SP. The first epidemiological study on the prevalence of cardiopulmonary and gastrointestinal parasites in cats and dogs from the Algarve region of Portugal using the FLOTAC technique. MSc Thesis, Universidade de Lisboa; 2017.

13. Raue K, Heuer L, Bohm C, Wolken S, Epe C, Strube C. 10-year parasitological examination results (2003 to 2012) of faecal samples from horses, ruminants, pigs, dogs, cats, rabbits and hedgehogs. Parasitol Res. 2017:116:3315-30.

14. Scaramozzino P, Carvelli A, lacoponi F, De Liberato C. Endoparasites in household and shelter dogs from Central Italy. Int J Vet Sci Med. 2018;6:45-7.

15. Beugnet F, Bourdeau P, Chalvet-Monfray K, Cozma V, Farkas R, Guillot J, et al. Parasites of domestic owned cats in Europe: co-infestations and risk factors. Parasit Vectors. 2014;7:291.

16. Mircean V, Titilincu A, Vasile C. Prevalence of endoparasites in household cat (Felis catus) populations from Transylvania (Romania) and association with risk factors. Vet Parasitol. 2010;171:163-6.

17. Sager H, Moret ChS, Grimm F, Deplazes P, Doherr MG, Gottstein B. Coprological study on intestinal helminths in Swiss dogs: temporal aspects of anthelminthic treatment. Parasitol Res. 2006;98:333-8.

18. Bourdeau P, Laboure L. Current situation of canine angiostrongylosis in France: result from a national survey with veterinary clinics. In: Proceedings of the Bayer Angiostrongylosis Forum, 19th Annual Congress of the European College of Veterinary Internal Medicine-Companion Animals, 9 September 2009, Porto, Portugal; 2009.
19. Morchón R, Carretón E, González Miguel J, Mellado Hernández I. Heartworm disease (Dirofilaria immitis) and their vectors in Europe-new distribution trends. Front Physiol. 2012;3:1-11.

20. Franc M, Cadiergues M, Marchand A, Bourdoiseau G, Bussieras J. Intestinal parasitism in dogs and cats. Results of an epidemiological survey in France. Rev Med Vet (Toulouse). 1997;148:247-50.

21. Coati N, Hellmann K, Mencke N, Epe C. Recent investigation on the prevalence of gastrointestinal nematodes in cats from France and Germany. Parasitol Res. 2003:90(Suppl. 3):146-7.

22. Oksanen A, Siles-Lucas M, Karamon J, Possenti A, Conraths FJ, Romig T, et al. The geographical distribution and prevalence of Echinococcus multilocularis in animals in the European Union and adjacent countries: a systematic review and meta-analysis. Parasit Vectors. 2016;9:519.

23. Combes B, Comte S, Raton V, Raoul F, Boué F, Umhang G, et al. Westward spread of Echinococcus multilocularis in foxes, France, 2005-2010. Emerg Infect Dis. 2012:18:2059.

24. Umhang G, Comte S, Hormaz V, Boucher JM, Raton V, Favier S, et al. Retrospective analyses of fox feces by real-time PCR to identify new endemic areas of Echinococcus multilocularis in France. Parasitol Res. 2016:115:4437-41.

25. Vuitton DA, Demonmerot F, Knapp J, Richou C, Grenouillet F, Chauchet $A$, et al. Clinical epidemiology of human AE in Europe. Vet Parasitol. 2015:213:110-20

26. Charbonnier A, Knapp J, Demonmerot F, Bresson-Hadni S, Raoul F, Grenouillet $F$, et al. A new data management system for the French National Registry of human alveolar echinococcosis cases. Parasite. 2014;21:69.

27. Deplazes P, Van Knapen F, Schweiger A, Overgaauw PA. Role of pet dogs and cats in the transmission of helminthic zoonoses in Europe, with a focus on echinococcosis and toxocarosis. Vet Parasitol. 2011;182:41-53.

28. Umhang G, Richomme C, Boucher JM, Hormaz V, Boue F. Prevalence survey and first molecular characterization of Echinococcus granulosus in France. Parasitol Res. 2013;112:1809-12.

29. Umhang G, Richomme C, Boué F. L'hydatidose porcine en Corse: épidémiologie et caractérisation moléculaire. Bull Epidémiol Santé Animale Alimentation. 2012. p. 6-10

30. Umhang G, Hormaz V, Peytavin C, Boucher J-M, Itié-Hafez S, Danan C, et al. Epidémiosurveillance d'Echinococcus granulosus à l'abattoir: résultats du plan de surveillance. Bull Epidémiol Santé Animale Alimentation. 2012;2012:8-12.

31. Schnyder M, Bilbrough G, Hafner C, Schaper R. Angiostrongylus vasorum "The French heartworm": a serological survey in dogs from France introduced by a brief historical review. Parasitol Res. 2017:116(Suppl. 1):31-40.

32. Montlaur L. Prévalence de l'angiostrongylose canine dans le sud-ouest de la France. Thèse d'exercice, Médecine vétérinaire, Ecole Nationale Vétérinaire de Toulouse-ENVT; 2015

33. Pantchev N, Schaper R, Limousin S, Norden N, Weise M, Lorentzen L. Occurrence of Dirofilaria immitis and tick-borne infections caused by Anaplasma phagocytophilum, Borrelia burgdorferi sensu lato and Ehrlichia canis in domestic dogs in France: results of a countrywide serologic survey. Parasitol Res. 2009;105(Suppl. 1):101-14.

34. Bourdeau P. Canine vector-borne diseases in France: information obtained from veterinary clinics in national surveys. In: Proceedings of the 3rd Canine Vector-Borne Diseases (CVBD) Symposium, Germany, 16-19 April 2008. p. 78-84.

35. Simón F, López-Belmonte J, Marcos-Atxutegi C, Morchón R, Martín-Pacho J. What is happening outside North America regarding human dirofilariasis? Vet Parasitol. 2005;133:181-9.

36. Simón F, Morchón R, González-Miguel J, Marcos-Atxutegi C, Siles-Lucas M. What is new about animal and human dirofilariosis? Trends Parasitol. 2009;25:404-9.

37. Pampiglione S, Rivasi F. Human dirofilariasis due to Dirofilaria (Nochtiella) repens: an update of world literature from 1995 to 2000. In: Genchi C, Rinaldi L, Cringoli G, editors. Dirofilaria immitis and D repens in dog and cat and human infections. Naples: Rolando Edirore; 2007. p. 81-116.

38. Tahir D, Bittar F, Barré-Cardi H, Sow D, Dahmani M, Mediannikov O, et al. Molecular survey of Dirofilaria immitis and Dirofilaria repens by new realtime TaqMan ${ }^{\circledR}$ PCR assay in dogs and mosquitoes (Diptera: Culicidae) in Corsica (France). Vet Parasitol. 2017;235:1-7.

39. Mérindol I, Ravier J-F, Halos L, Guillot J. Questionnaire-based survey on distribution of canine ocular thelaziosis in southwestern France. Vet Parasitol. 2018:253:26-9. 
40. Otranto D, Dutto M. Human thelaziasis, Europe. Emerg Infect Dis. 2008; 14:647.

41. ESCCAP. Worm control in dogs and cats. In: ESCCAP Guideline 01 Third Edition. 2017. http://www.esccap.org/uploads/docs/0x0o7jda_ESCCA P_Guideline_01_Third_Edition_July_2017.pdf. Accessed 21 Jun 2018.

42. Umhang $G$, Raton V, Comte S, Hormaz V, Boucher JM, Combes B, et al. Echinococcus multilocularis in dogs from two French endemic areas: no evidence of infection but hazardous deworming practices. Vet Parasitol. 2012;188:301-5.

43. McNamara J, Drake J, Wiseman S, Wright I. Survey of European pet owners quantifying endoparasitic infection risk and implications for deworming recommendations. Parasit Vectors. 2018;11:571.

44. Gates MC, Nolan TJ. Risk factors for endoparasitism in dogs: retrospective case-control study of 6578 veterinary teaching hospital cases. J Small Anim Pract. 2009;50:636-40.

45. Nijsse R, Ploeger HW, Wagenaar JA, Mughini-Gras L. Toxocara canis in household dogs: prevalence, risk factors and owners' attitude towards deworming. Parasitol Res. 2015;114:561-9.

46. Schlesinger DP, Joffe DJ. Raw food diets in companion animals: a critical review. Can Vet J. 2011;52:50.

47. Beugnet F, Guillot J, Polack B, Chermette R. Survey of dogs and cats gastro-intestinal parasites in Paris region. Rev Med Vet (Toulouse). 2000;151:443-6.

48. Overgaauw PA, van Knapen F. Veterinary and public health aspects of Toxocara spp. Vet Parasitol. 2013;193:398-403.

49. Stull JW, Carr AP, Chomel BB, Berghaus RD, Hird DW. Small animal deworming protocols, client education, and veterinarian perception of zoonotic parasites in western Canada. Can Vet J. 2007;48:269-76.

50. Nijsse R, Ploeger HW, Wagenaar JA, Mughini-Gras L. Prevalence and risk factors for patent Toxocara infections in cats and cat owners' attitude towards deworming. Parasitol Res. 2016;115:4519-25.
51. Matos M, Alho AM, Owen SP, Nunes T, de Carvalho LM. Parasite control practices and public perception of parasitic diseases: a survey of dog and cat owners. Prev Vet Med. 2015;122:174-80.

52. Kapel CM, Torgerson P, Thompson R, Deplazes P. Reproductive potential of Echinococcus multilocularis in experimentally infected foxes, dogs, raccoon dogs and cats. Int J Parasitol. 2006;36:79-86.

53. Van Cauteren D, Millon L, De Valk H, Grenouillet F. Retrospective study of human cystic echinococcosis over the past decade in France, using a nationwide hospital medical information database. Parasitol Res. 2016;115:4261-5

54. Otranto D, Dantas-Torres F, Mallia E, DiGeronimo PM, Brianti E, Testini $\mathrm{G}$, et al. Thelazia callipaeda (Spirurida, Thelaziidae) in wild animals: report of new host species and ecological implications. Vet Parasitol. 2009;166:262-7.

55. Otranto D, Brianti E, Cantacessi C, Lia R, Máca J. The zoophilic fruitfly Phortica variegata: morphology, ecology and biological niche. Med Vet Entomol. 2006;20:358-64.

56. Bowman DD. Heartworms, macrocyclic lactones, and the specter of resistance to prevention in the United States. Parasit Vectors. 2012;5:138

57. Farrell SH, Truscott JE, Anderson RM. The importance of patient compliance in repeated rounds of mass drug administration (MDA) for the elimination of intestinal helminth transmission. Parasit Vectors. 2017;10:291.

58. Nijsse R, Mughini-Gras L, Wagenaar JA, Franssen F, Ploeger HW. Environmental contamination with Toxocara eggs: a quantitative approach to estimate the relative contributions of dogs, cats and foxes, and to assess the efficacy of advised interventions in dogs. Parasit Vectors. 2015;8:397.

\section{Publisher's Note}

Springer Nature remains neutral with regard to jurisdictional claims in published maps and institutional affiliations.
Ready to submit your research? Choose BMC and benefit from:

- fast, convenient online submission

- thorough peer review by experienced researchers in your field

- rapid publication on acceptance

- support for research data, including large and complex data types

- gold Open Access which fosters wider collaboration and increased citations

- maximum visibility for your research: over 100M website views per year

At BMC, research is always in progress.

Learn more biomedcentral.com/submissions 